\title{
Sediment-Induced Amplification in the Northeastern United States: a Case Study in Providence, Rhode Island
}

\author{
by Karen M. Fischer, Lynn A. Salvati, Susan E. Hough, Edward Gonzalez, \\ Chad E. Nelsen, and Erich G. Roth
}

\begin{abstract}
We employed ambient-noise measurements to assess the potential for seismic site response in sediment-filled valleys that intersect beneath downtown Providence, Rhode Island. At eight valley stations and at two sites on an adjacent bedrock highland, we recorded ground motion from two types of sources: pile drivers at a local construction site and ambient microtremors. At all valley sites where sediment thicknesses exceed $10 \mathrm{~m}$, spectral ratios contain amplitude peaks at frequencies of 1.5 to $3.0 \mathrm{~Hz}$. In contrast, spectral ratios from the two sites on the bedrock highland where sediment cover is less than 4-m thick are relatively flat within this frequency range. A variety of borehole logs identified two fundamental sediment types (soft sediment and a consolidated glacial till) and were used to map layer thicknesses over the entire study region. Refraction data constrained $P$-wave velocity in the bedrock to be $3680 \pm 160 \mathrm{~m} / \mathrm{sec}$ and indicated two soft-sediment layers with $P$-wave velocities of $300 \pm 50$ and $1580 \pm 120 \mathrm{~m} / \mathrm{sec}$. Using a one-dimensional reflection matrix technique, we matched the spectral-ratio peak observed at each valley site with the frequency of fundamental resonance predicted for local layer thicknesses and velocities. A positive correlation between the best-fitting soft-sediment velocities and bedrock depth may reflect greater compaction in the deepest sediments or a locally twodimensional sediment resonance at the deepest sediment sites. We conclude that unconsolidated sediment layers under downtown Providence have the potential to amplify earthquake ground motion at frequencies damaging to engineered structures.
\end{abstract}

\section{Introduction}

More than three decades ago, Kanai and Tanaka (1961) suggested that ambient-noise characteristics might be representative of local site amplification at sedimentary sites. Subsequent investigations have explored the use of both longer period (1- to 5-sec) microtremors (Ohta et al., 1978; Kagami et al., 1982, 1986) and higher frequency microseisms for the characterization of site response [see Field $e t$ al. (1990) for a review].

In recent years, interest in developing cost-effective methods to characterize site response for microzonation has motivated numerous studies to further investigate the use of ambient-noise measurements to characterize sediment-induced amplification of ground motions at sediment sites. Agreement between response functions estimated using ambient noise and weak/strong motion has been demonstrated in several regions, including Mexico City (Lermo et al., 1988), Armenia (Field et al., 1995), and the San Francisco Bay Area (Field and Jacob, 1995). In other areas, ambient noise has been shown to be dominated by strong resonant frequencies, which have been successfully modeled as site response (e.g., Field et al., 1990; Hough et al., 1992). How- ever, studies in both California and Japan have argued that response functions inferred from ambient noise and weak/ strong motion differ significantly (Borcherdt, 1970; Udwadia and Trifunac, 1973; Okamato, 1973).

Analysis of strong-motion data from the 1989 Loma Prieta earthquake reveals that the frequencies of peak response in weak- and strong-motion data agree, but that weak-motion response functions at soft-soil sites can overestimate the amplitude of strong-motion amplification. Darragh and Shakal (1991) argue that the soft-soil site-amplification factors are reduced at higher accelerations by nonlinear behavior in the soils (also see Chin and Aki, 1991). In general, ambient noise is not expected to characterize site response to ground motion that is strong enough to cause nonlinear sediment behavior (e.g. Beresnev et al., 1995). However, rapid and cost-effective characterization of linear site response is an important first step in microzonation. Recently, Nakamura's method (Nakamura, 1989), in which ambient-noise amplification is estimated from a ratio of horizontal to vertical recordings at a site, has been shown to isolate reliable amplification factors in regions where they 
cannot be inferred from raw spectra (Lermo et al., 1993; Field and Jacob, 1995; Field et al., 1995). Theoretical justification for this method is given by Finn (1991), Lermo et al. (1993), and Field and Jacob (1993).

Because of the low level of background seismicity in eastern North America, few weak-motion sources and fewer still strong ground-motion sources are available for the assessment of site response. Furthermore, in densely populated urban areas, the recording of even weak ground motion is problematic, and the ambient-noise method is often the sole opportunity to provide observational constraints on expected ground-motion amplifications. Providence, Rhode Island, is typical of numerous eastern United States coastal cities in that some of its most densely built areas are situated on sedimentary valleys where the potential for significant groundmotion amplification exists. Beneath the downtown area of the city, three branches of a bedrock valley system intersect. The valleys are 40- to 60-m deep (measured from the surface) and are filled with a layer of compacted glacial till under layers of unconsolidated sand, gravel, mud, and artificial fill (Smith, 1956; Bierschenk, 1959). To the east of this area lies a bedrock highland covered by a thin $(0$ to $5 \mathrm{~m})$ mantle of glacial sediment (Fig. 1).

In a preliminary study based on ambient microtremor data, Fischer and Hough (1992) found that at sites located in the river valleys beneath downtown Providence, groundmotion spectra indicated amplification of energy in the range of 1 to $3 \mathrm{~Hz}$. This spectral peak occurs in the spectra from sediment sites and in spectral ratios that reference sediment to hardrock stations. Fischer and Hough (1992) modeled these spectra with theoretical transfer functions for onedimensional models that approximate basin structure and found that the spectral peak can be interpreted as the fundamental resonance of low-impedance surface sediment layers. The analysis presented here improves upon the earlier study in several ways: (1) by recording pile drivers in addition to ambient microtremors, we investigate the sensitivity of the ambient-noise method to conspicuous isolated local noise sources; (2) our use of horizontal to vertical spectral ratios at a given site (Nakamura's method) instead of sediment/bedrock ratios removes the possibility of bias from differing ground-motion sources at valley and reference sites; and (3) further analysis of geotechnical data improves our three-dimensional model of basin structure.

\section{Observed Ground Motion}

\section{Sources: Ambient Microtremors and Pile Drivers}

In October of 1990 and November of 1991, we deployed portable seismic instruments at 10 sites within the city of Providence, Rhode Island. Eight stations were located in two sediment-filled bedrock valleys that intersect beneath downtown Providence, and two were on an adjacent bedrock highland with minimal sediment cover (Fig. 1). In 1991, we recorded ground motion from two types of sources: pile
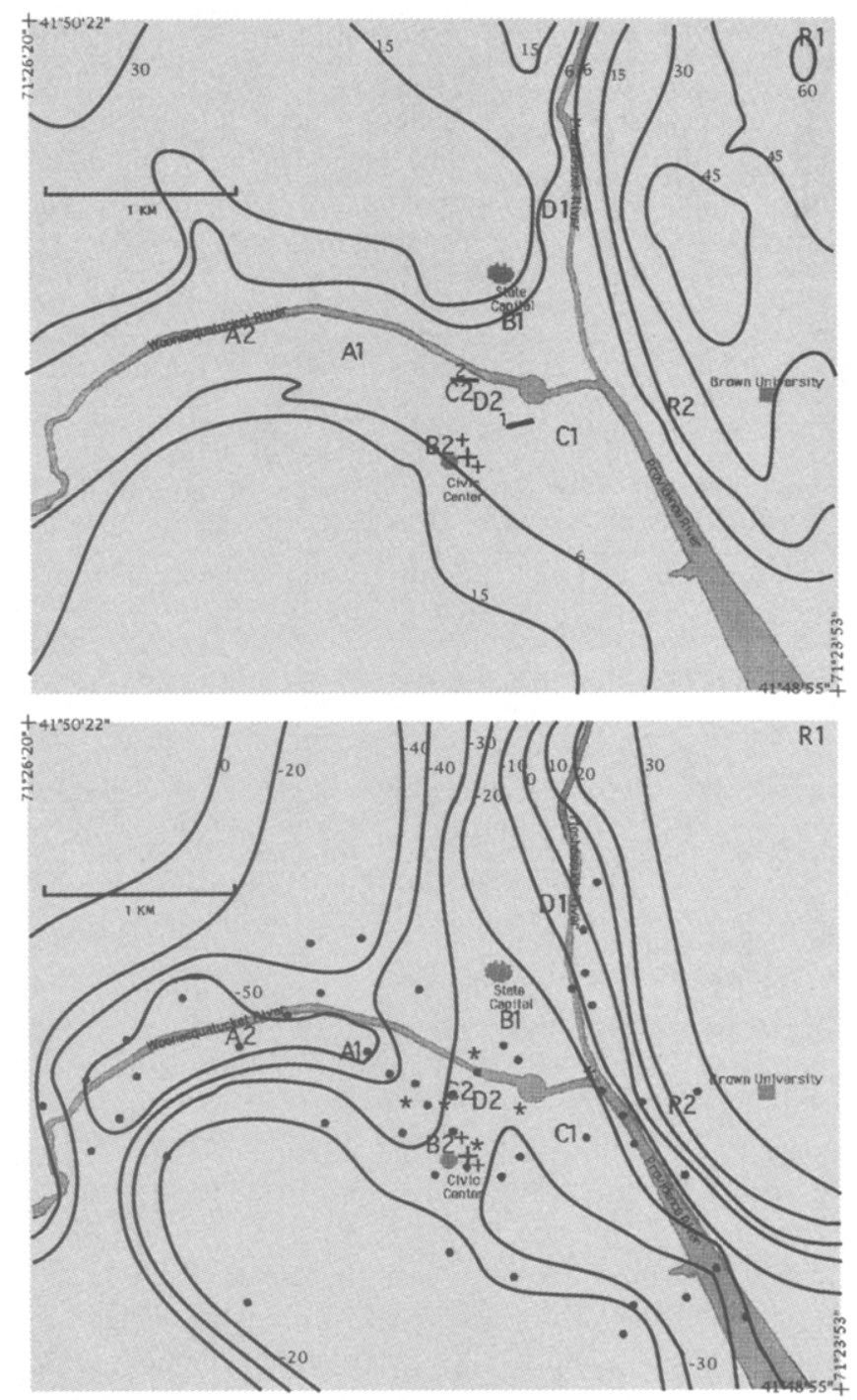

Figure 1. Map of survey area surrounding river valleys in Providence, Rhode Island. (a) Contours show surface topography relative to sea level (contours at $6,15,30,45$, and $60 \mathrm{~m}$ ). Station locations are shown by labels A1 through R2. Plusses show locations of pile drivers; the largest plus indicates the source of the ground motions in Figure 2. Line segment 1 shows the location of the bedrock velocity refraction experiment; line segment 2 shows the location of the sediment velocity refraction experiment. (b) Contours show the bedrock surface relative to sea level (10-m contour interval); contours above sea level and at margins of map are less well constrained. Station locations are shown by labels A1 through R2. Dots indicate individual boreholes and wells used to constrain subsurface structure; asterisks represent groups of 10 to 30 densely spaced boreholes from recent construction projects. 
drivers at a local construction site and ambient microtremors. During 1990 , we recorded only ambient microtremor sources. Data were collected over 2-min windows in 1990 and over 9-min windows in 1991, using Kinemetrics 5-sec sensors and EDA PRS-4 recorders. A typical time series for station D2 during which the pile drivers were active (Fig. 2a) reveals a repeated waveform pattern generated by each drop of the pile-driver mass. The time interval between pile-driver drops for this record was approximately $0.94 \rightarrow 0.9 \mathrm{sec}$. The particle motions of the largest amplitude phases on the vertical and radial components manifest a retrograde elliptical particle motion that is consistent with Rayleigh-wave energy (Fig. 2a). In contrast, a time series at station D2 during which no pile-driver source was active shows the apparently unorganized ground motions characteristic of ambient microtremors (Fig. 2b). For stations at distances of more than 0.5 $\mathrm{km}$ from the pile drivers, pile-driver phases are at best weakly visible, and most pile-driver and ambient microtremor seismograms are indistinguishable.

\section{Ground-Motion Spectra}

To compare the frequency content of pile-driver and ambient microtremor seismograms in the 1991 data, we computed spectra for 2-min windows when pile drivers were active and inactive (Fig. 3). For the 1990 data no pile drivers were active, and spectra were computed from $40-\mathrm{sec}$ windows. To compute spectra, we applied a cosine taper to the first and last $5 \%$ of the time series, computed fast Fourier transforms, and smoothed using a boxcar filter that averaged amplitudes over a $\pm 0.3-\mathrm{Hz}$ window. The time series were not corrected for instrument response. However, sensor response to velocity is relatively flat at frequencies above 0.2 $\mathrm{Hz}$, so the effect of instrument response in the Figure $3 \mathrm{spec}-$ tra are small. At frequencies of 4 to $5 \mathrm{~Hz}$ and above, spectra for stations within $0.5 \mathrm{~km}$ of the pile driver (B2, C2, and D2) contain regularly spaced peaks in amplitude that are characteristic of pile-driver-generated ground motions (e.g., Field et al., 1990) and are quite distinct from the ambient microtremor spectra. At stations more distant from the piledriver site, the typical pile-driver spectral peaks are much less pronounced, indicating that pile-driver phases are rapidly attenuated by the soft valley sediments. At frequencies of $4 \mathrm{~Hz}$ and less, the pile-driver and microtremor spectral shapes and amplitudes at each site are very similar and are approximately uniform in time. This result argues that the spectral character of ambient noise at lower frequencies at each site is robust and is not sensitive to the details of local noise sources.

To estimate site response at each station, we employed a technique proposed by Nakamura (1989) that represents a site transfer function by the ratio of the station's horizontalcomponent ground-motion spectrum to the station's verticalcomponent spectrum. This technique contrasts with the more commonly employed approach of referencing sediment site spectra to a hardrock site. Nakamura's approach was formulated under the assumption that microtremor motion is
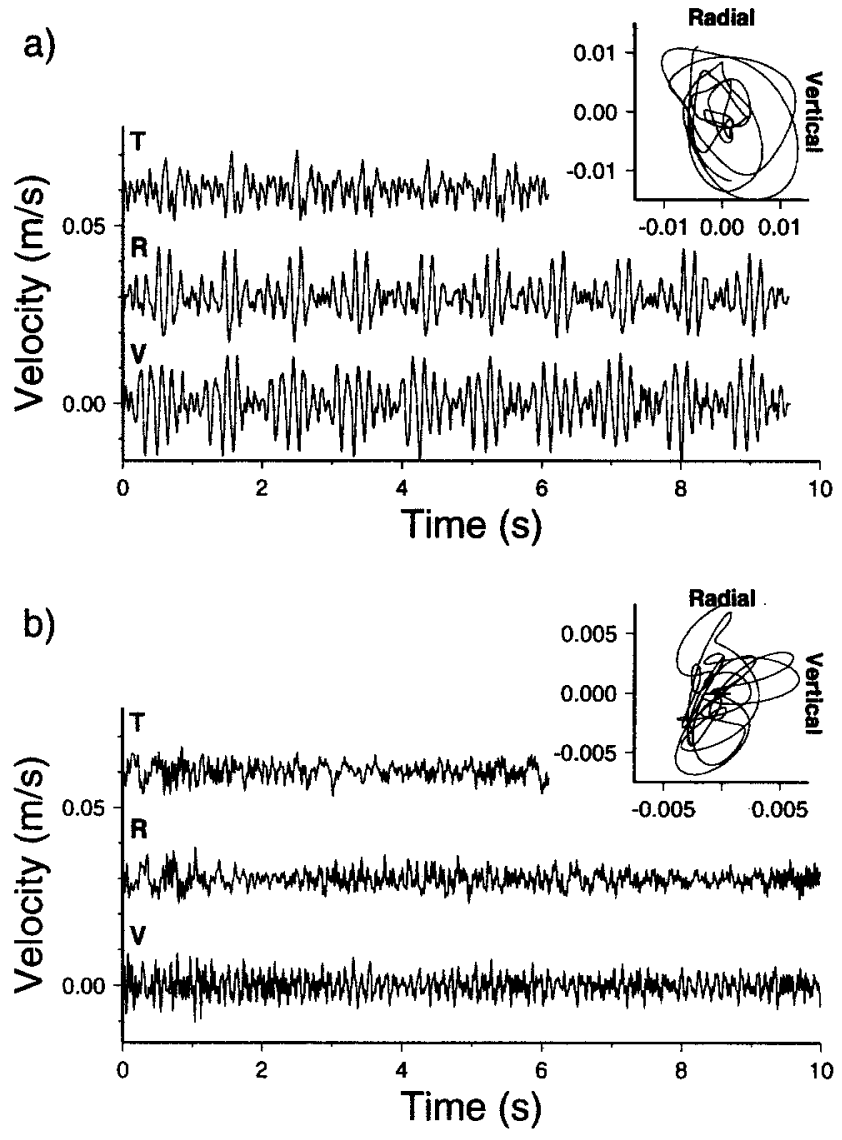

Figure 2. (a) Seismogram from station D2 recorded while a pile driver (location shown by the large plus in Fig. 1) was striking the ground at an interval of approximately $0.94 \mathrm{sec}$. The particle motion of the dominant phase on the radial and vertical components is consistent with Rayleigh-wave energy. (b) Seismogram from station $\mathrm{D} 2$ during which no pile-driver source was active. Component reference frames are the same in (a) and (b). Insets show radial versus vertical particle motion for the portion of each seismogram between 3 and 4 sec.

composed primarily of Rayleigh-wave energy. To investigate the applicability of Nakamura's technique to $S$ phases, Lermo et al. (1993) used theoretical $S V$ transfer functions to compute ratios of vertical to horizontal $S$-wave spectra at the surface and ratios of spectra at the surface to spectra at the base of the sediment column. They found that the horizontal/ vertical spectral ratios match the shape of the sediment/ bedrock ratios and that the amplitudes of the two types of transfer functions agree for incidence angles of more than $50^{\circ}$. Field and Jacob (1995) provide additional theoretical justification for the method, demonstrating that the method successfully recovers the theoretical site response from synthetic ambient-noise data generated from a random distribution of surficial white-noise sources. Empirical comparisons of the two techniques (Lermo et al., 1993; Field and Jacob, 1995) indicate that they yield similar representations of site response, and that Nakamura's method can success-- 

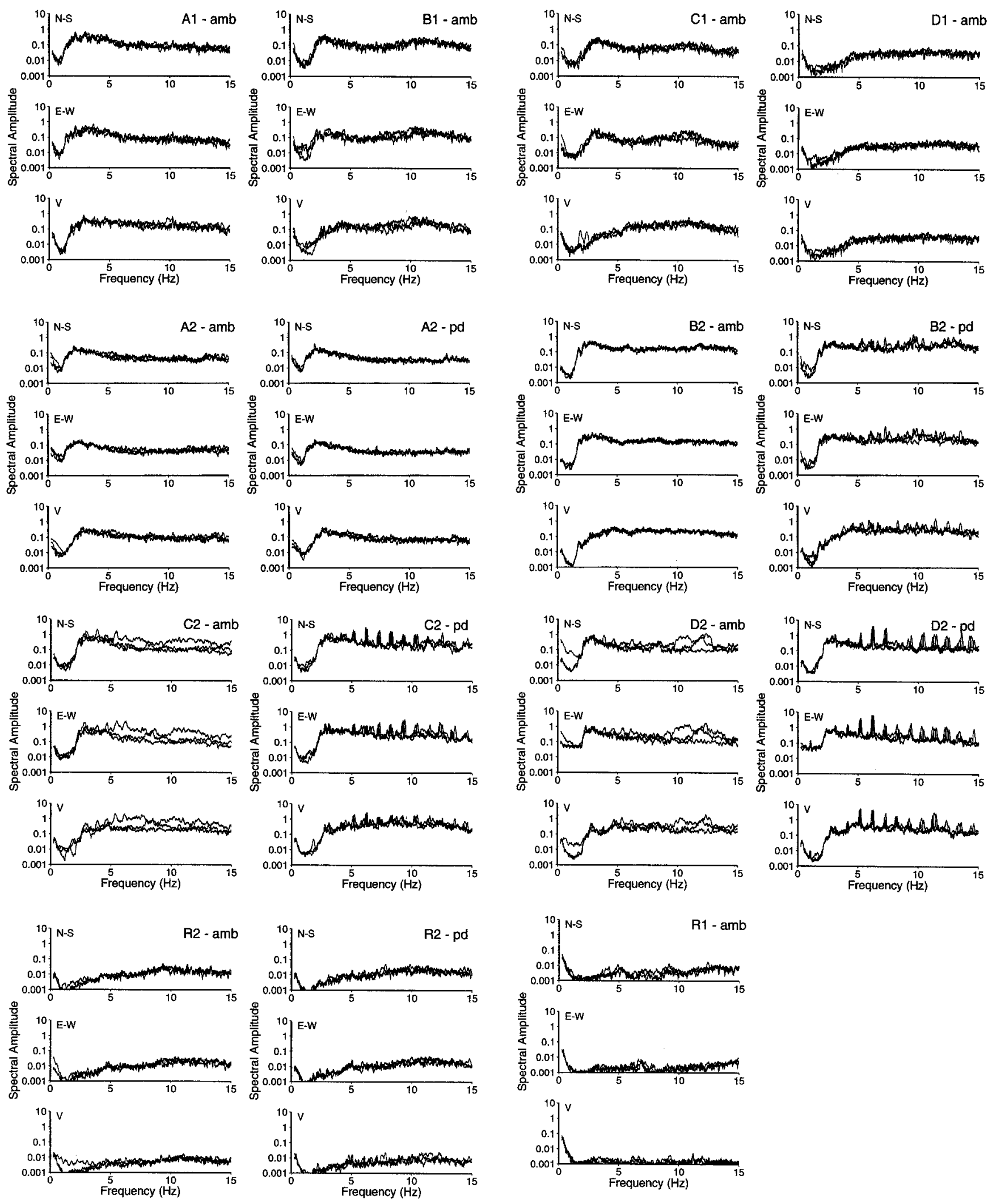

Figure 3. Ground-motion spectra for valley and bedrock stations. Each line is the smoothed Fourier transform of a velocity seismogram. For the 1990 sites (A1, B1, C1, D1, R1) spectra were computed from 40 -sec windows with no pile-driver activity. For the 1991 data (A2, B2, C2, D2, R2) spectra were computed from 2-min. windows when pile drivers were both active and inactive. Each frame contains spectra from three different time windows and is labeled with the station name and component; "pd" and "amb" indicate that pile drivers were active and inactive, respectively. At frequencies of 4 to $5 \mathrm{~Hz}$ and above, spectra for stations near active pile drivers (B2, C2, and D2) contain regularly spaced peaks in amplitude that are characteristic of pile-driver generated ground motions. At frequencies of $4 \mathrm{~Hz}$ and less, the pile-driver and microtremor spectral shapes and amplitudes at each site are very similar. 
fully identify resonance frequencies in cases where no suitable reference site exists. We chose Nakamura's approach for our analysis because it is free of assumptions inherent in the sediment/bedrock spectral-ratio method regarding groundmotion sources: that both stations are recording the same source along a similar path (a requirement not in general met by our data set) or that the spectral content of sources recorded at either site is statistically similar (Field et al., 1990) (a requirement unverified by our dataset).

To compute transfer functions for each site, we divided each horizontal-component spectrum shown in Figure 3 by the vertical-component spectrum for the same time window and computed the mean of the individual NS/V and EW/V ratios (Fig. 4). At all sites within the bedrock valleys where sediment thicknesses exceed $10 \mathrm{~m}$ (A1, A2, B1, B2, C1, C2, D2) (Fig. 1), spectral ratios contain amplitude peaks at frequencies of 1.5 to $3.0 \mathrm{~Hz}$. In contrast, spectral ratios from the two sites on the bedrock highland where sediment cover is less than 4-m thick ( $\mathrm{R} 1$ and $\mathrm{R} 2$ ) are relatively flat at frequencies of 0.2 to $10.0 \mathrm{~Hz}$. The contrast between the spectral ratios for deep-sediment and bedrock stations suggests that the $1.5-$ to $3.0-\mathrm{Hz}$ peak observed at deep-sediment sites represents a resonance of ambient microtremor energy within the valley sediments. The spectral ratios at site D1, located near the edge of the northern valley, contain no evidence of amplification in the $1.5-$ to $3.0-\mathrm{Hz}$ range, although they do show larger amplitude ratios at higher frequencies (Fig. 4d). The lack of a well-defined low-frequency resonance at this site may be explained by the smaller depth to bedrock (roughly $8 \mathrm{~m}$ ) and its location near the transition from sediment-filled valley to bedrock highland. To investigate the hypothesis that the spectral-ratio peaks for the deep-sediment sites represent sediment resonance, we constrained the structure of the valley sediment and bedrock layers and modeled the observed spectral ratios at each valley site with onedimensional transfer functions.

\section{Three-Dimensional Basin Structure}

\section{Borehole and Well Data}

We constrained the geologic structure beneath our study area with a variety of geotechnical data. Logs from 150 boreholes collected in four recent construction projects close to sites B1, B2, C2, and D2 (Haley and Aldrich, Inc., 1990a, b; C. E. Maguire Inc., 1986, 1990) were synthesized into detailed maps of bedrock depth and sediment isopachs. They identify two fundamental sediment layers: a mixture of unconsolidated artificial fill and fluvial sediments on top of consolidated glacial till. To map layer thicknesses over the entire study region (Fig. 1), the construction-site data were combined with boreholes and profiles from a recent sewer overflow abatement study (Louis Berger and Associates, Inc., 1992) and 44 older well-log measurements compiled by the U.S. Geological Survey for water resources assessment (Bierschenk, 1959). Contours of surface topography were adopted from the U.S. Geological Survey 7.5-min topographic quadrangle map for Providence, Rhode Island (1975), and updated in areas of recent construction using borehole data. This synthesis reveals an E-W-trending bedrock valley beneath the Woonasquatucket River (maximum depth 50 to $60 \mathrm{~m}$ ) that intersects a smaller N-S-trending bedrock valley (maximum depth 40 to $50 \mathrm{~m}$ ) (Fig. 1b). The basin and saddle structure formed by this intersection opens to the south in a NW-SE bedrock valley (maximum depth 30 to $40 \mathrm{~m}$ ) whose axis lies just west of the Providence River. Within the valleys, the thickness of the till layer varies from 3 to $15 \mathrm{~m}$ and is best constrained in the vicinity of sites $\mathrm{A} 1, \mathrm{~B} 2, \mathrm{C} 2$, and D2.

\section{Seismic Refraction Data}

To obtain a quantitative estimate of sediment and bedrock velocity structure, we collected seismic refraction data in two locations. In the first refraction experiment (location shown by line segment 1 in Fig. 1), a single pile-driver drop was recorded over a W-E 12-channel refraction line with a sensor spacing of $7.0 \mathrm{~m}$ and a distance between the source and the nearest sensor of roughly $250 \mathrm{~m}$. Linear regression analysis performed on the resulting travel times (Fig. 5a) yields $P$-wave velocity for the bedrock layer of $3680 \pm 160$ $\mathrm{m} / \mathrm{sec}$ (error bars correspond to a $95 \%$ confidence level). Bedrock beneath the entire study area and adjacent highland is a sandstone/conglomerate (Bierschenk, 1959), and a $V_{p}$ of $3680 \pm 160 \mathrm{~m} / \mathrm{sec}$ is consistent with bedrock $V_{p}$ 's obtained by refraction lines on the bedrock highland (D. W. Forsyth, personal comm., 1991).

In the second refraction experiment (location shown by line segment 2 in Fig. 1), we recorded stacked sledgehammer hits at distances of 1 to $96 \mathrm{~m}$ on two E-W lines with sensor spacings of 1.0 and $8.5 \mathrm{~m}$ and on two W-E lines with spacings of 7.0 and $8.5 \mathrm{~m}$. The travel time versus distance relationships on the forward and reverse lines are consistent (Fig. 5b), indicating that structure beneath the refraction lines may be accurately approximated with a horizontally stratified medium. In modeling the travel-time data, we employed a four-layer velocity model. We assumed that the boundaries between the soft sediment, till, and bedrock layers constrained by nearby boreholes represent the primary velocity contrasts in the deeper part of the sediment column, and fixed the depth to the top of the till layer at $19.2 \mathrm{~m}$ and the depth to the top of the bedrock layer at $23.7 \mathrm{~m}$. Borehole records document a sharp increase in blow counts at the top of the till layer and support the assumption of an impedance contrast at this depth (Haley and Aldrich, Inc., 1990a, b). In addition, to account for the change in the slope of the traveltime curve at 9- to $10-\mathrm{m}$ distance, we included a velocity discontinuity at 3.8-m depth. To obtain model velocities, we fixed the bedrock $V_{p}$ at $3680 \mathrm{~m} / \mathrm{sec}$ and determined crossover distances for the phases from each layer by forward modeling. We then performed a linear regression on the travel-time data within the first and second branches of the 
a)
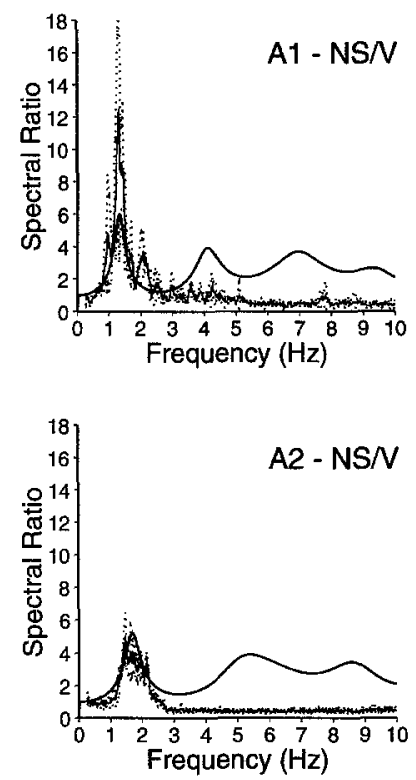

c)
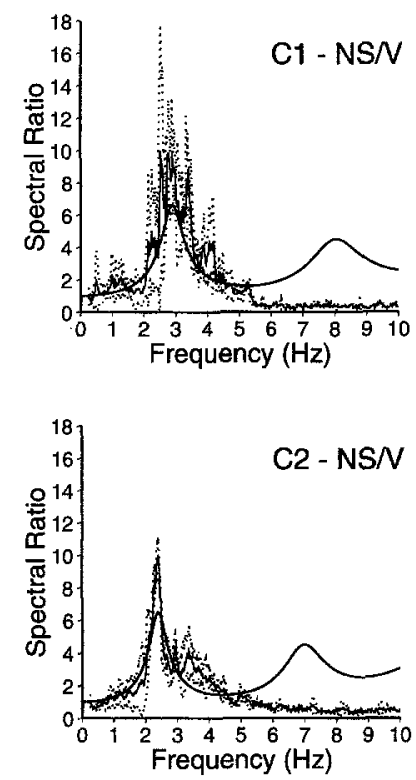
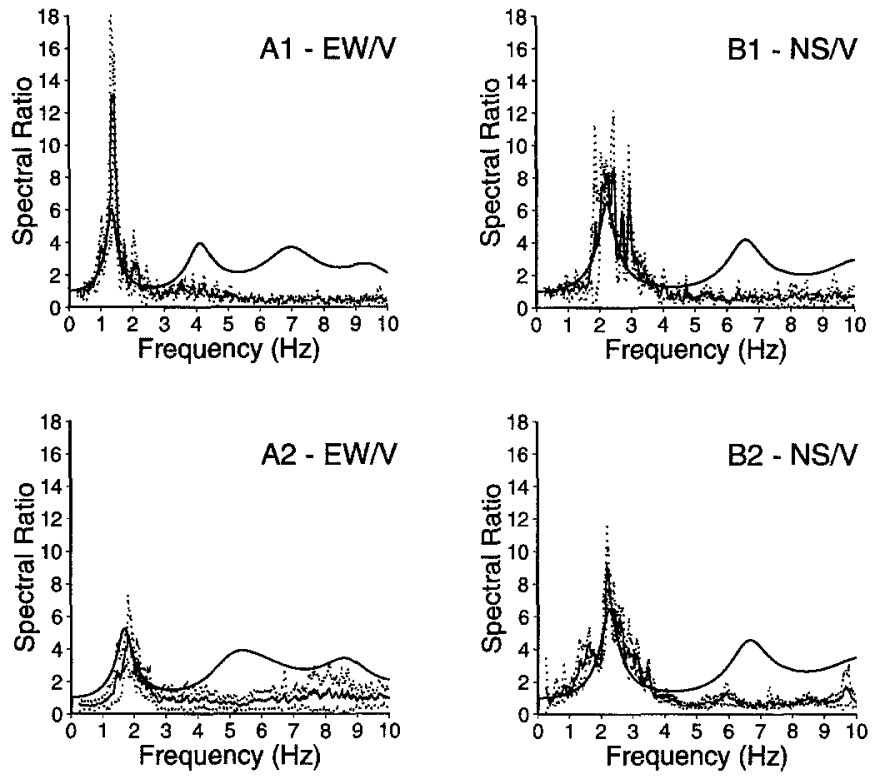

d)
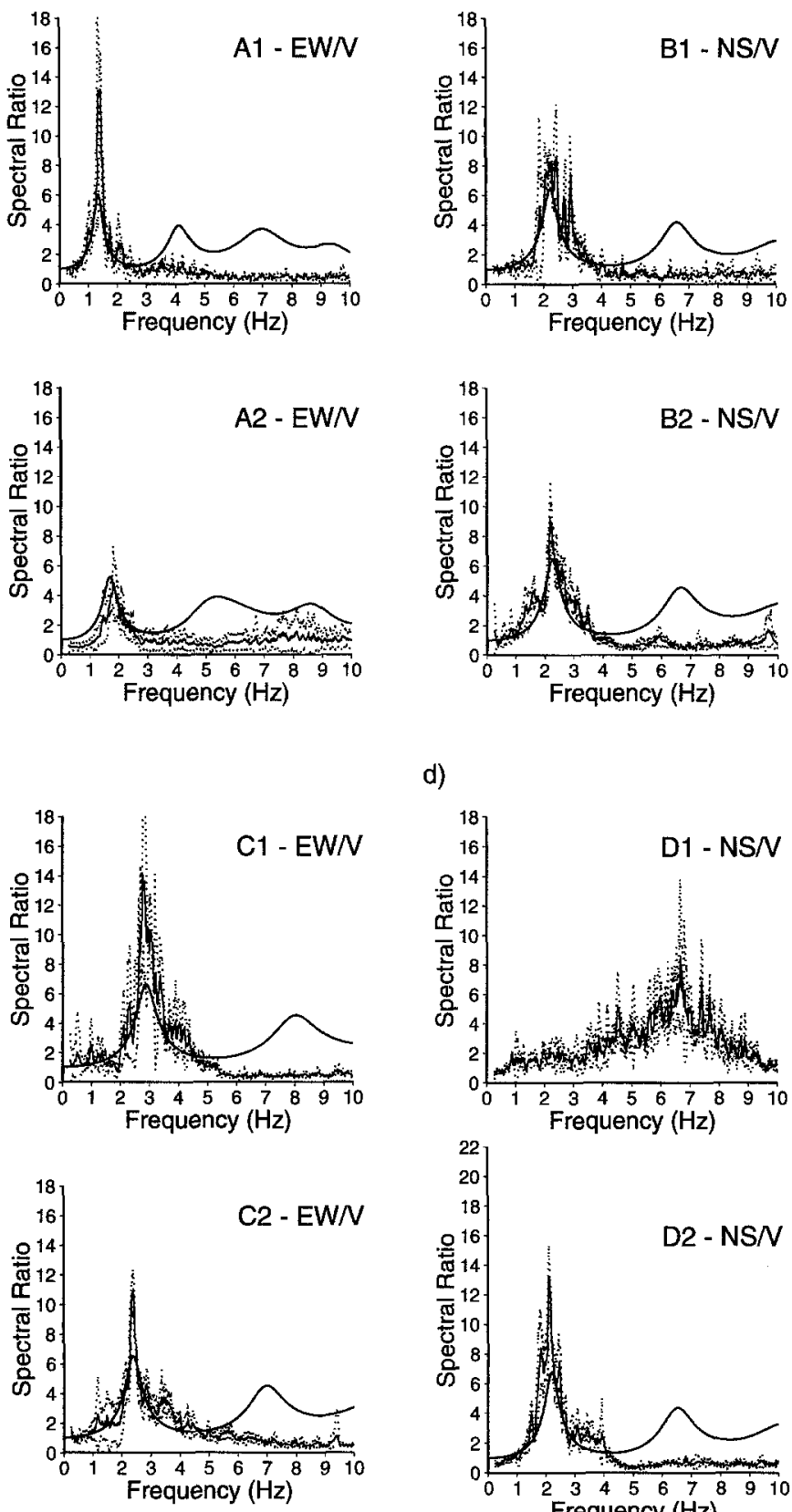

b)
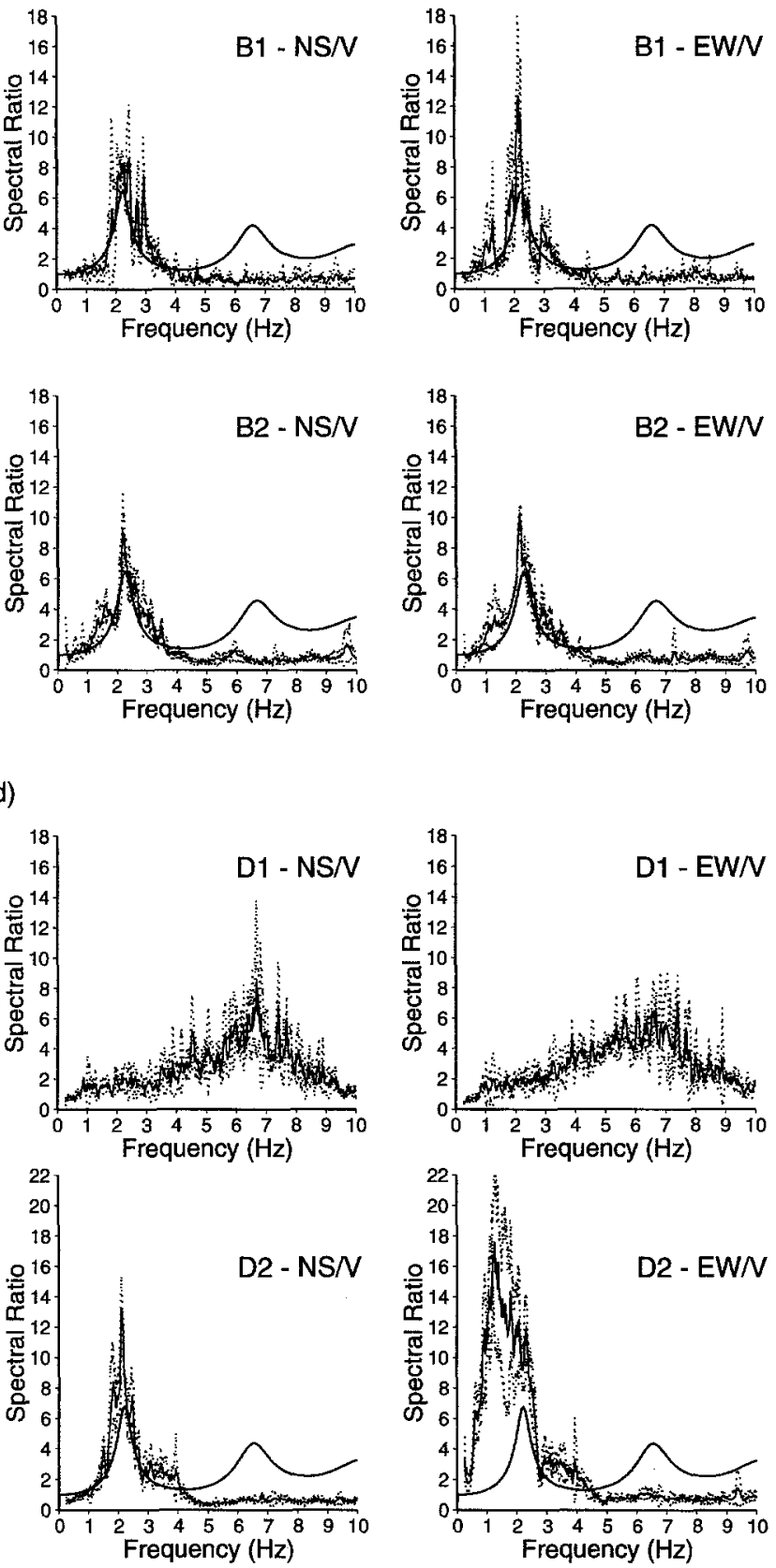

travel-time curve and determined velocities of $300 \pm 50$ and $1580 \pm 120 \mathrm{~m} / \mathrm{sec}$ for the two soft sediment layers.

The $V_{p}$ value of $300 \pm 50 \mathrm{~m} / \mathrm{s}$ obtained for the top layer is very low, approximately the $P$-wave velocity of air, but this value is not unreasonable for loose, dry soils. Another interpretation of the first arrival at distances of 0 to $10 \mathrm{~m}$ is that it is an air wave; air phases are not uncommon at short distances on the type of refraction equipment used in this experiment. However, this second interpretation implies that the direct $P$ wave in the shallow soil layer at distances of 0 to $10 \mathrm{~m}$ is not observed as a first arrival. In either case, the
$P$-wave velocity in the shallowest sediments must be substantially less than the value of $1580 \pm 120 \mathrm{~m} / \mathrm{sec}$ obtained for the bulk of the unconsolidated sediments. When modeling the ground-motion spectra, we chose to include a 3.8m-thick low-velocity layer at the surface of our velocity model. However, the exact thickness and velocity of this layer has little impact on the overall modeling results or on the conclusions of this study.

The till layer $V_{p}$ is only loosely constrained by a few of the most distant line 2 refraction data because the minimum cross-over distance for the refracted phase sampling the till 
e)
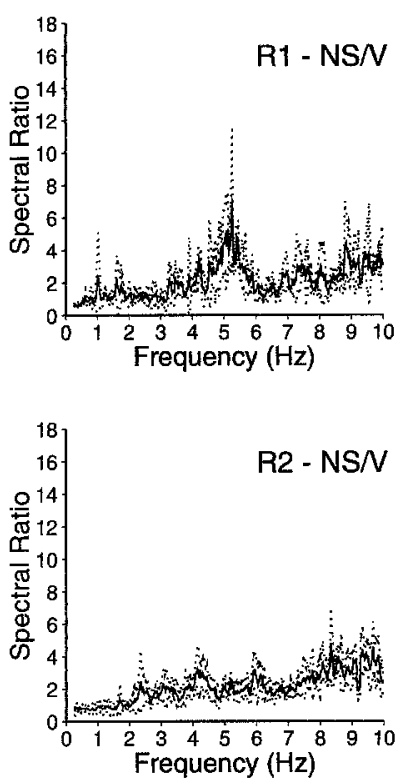
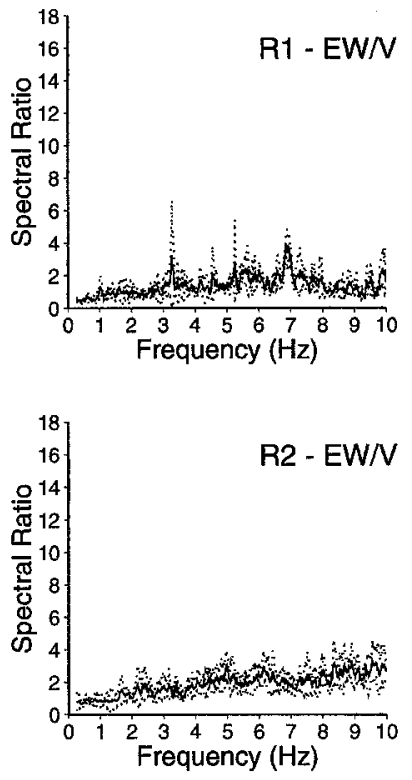

Figure 4. (Above and facing page.) Transfer functions for each station represented by ratios of horizontal to vertical ground-motion spectra. In each frame, the thinner solid line is the mean of the spectral ratios $(\mathrm{NS} / V$ or $\mathrm{EW} / V)$ obtained for the individual spectra shown in Figure 3; dotted lines show one standard deviation. Bold solid lines are the theoretical transfer functions computed for a four-layer velocity model. Layer thicknesses at each station are in Table 1; shear-wave velocities assumed in this figure for bedrock, till, and layer 1 are 2125,1400 , and 120 $\mathrm{m} / \mathrm{sec}$. Layer-2 velocities are in Table 2 ; the layer-2 velocity used for station D2 is $225 \mathrm{~m} / \mathrm{sec}$. Observed spectral ratios contain peaks at frequencies $<4 \mathrm{~Hz}$ for all valley sites where sediment thicknesses exceed 10 m (A1, A2, B1, B2, C1, C2, D2), but not at sites on the bedrock highland (R1 and R2). With the exception of the $E W / V$ ratio at station D2, the frequency of the spectral-ratio peaks at each deep sediment site is well fit by the frequency of fundamental resonance in the transfer function predicted for that station.

layer is $70 \mathrm{~m} . V_{p}$ values of less than $2700 \mathrm{~m} / \mathrm{sec}$ significantly overpredict travel time at distances of more than $85 \mathrm{~m}$, but any $V_{p}$ value in the range of 2700 to $3680 \mathrm{~m} / \mathrm{sec}$ provides an adequate fit to the data. In Figure $5 \mathrm{~b}$, predicted travel times are shown for a till $V_{p}$ value of $2900 \mathrm{~m} / \mathrm{sec}$. While the $V_{p}$ values obtained by the regression analysis provide a good average fit to the data, the four-layer model likely oversimplifies real velocity structure. The travel times for the deeper soft-sediment layer (layer 2) show a small decrease in slope about the best linear fit (Fig. 5b). This curvature suggests that $V_{p}$ within this layer increases with depth, perhaps because of compaction of the unconsolidated sediments.

\section{Modeling Sediment Resonance}

Our goal in modeling the observed spectral ratios was to determine whether the peaks observed at 1.5 to $3.0 \mathrm{~Hz}$ at

the valley stations can be explained by shear-wave resonance in the sediment layers. We compared the spectral ratios observed at each valley site to transfer functions predicted by one-dimensional models appropriate to the layer thicknesses beneath each site. This approach assumes that the spectral content of ambient noise at a given site is most sensitive to the structure directly beneath it, and that this structure may be approximated by a one-dimensional average. Although the shape of the valley bedrock contours is complex in map view (Fig. 1), a one-dimensional approximation to this structure is appropriate for the transfer-function calculations; the valleys are very shallow with respect to their widths. According to the plane-wave calculations of Bard and Bouchon (1985), the valleys should produce a primarily vertical shearwave resonance for a reasonable range for sediment/bedrock velocity contrasts. To compute the theoretical response of the sediment column, we used the reflection matrix technique of Kennett and Kerry (1979).

The refraction data collected in downtown Providence provide constraints on $P$-wave velocities in the bedrock and sediments but do not independently characterize $S$-wave velocity structure at each site. Rather, for each model layer we determined a range of $V_{s}$ values that are consistent with both the $V_{p}$ values from the refraction data and shallow sediment $V_{s}$ values from other regions. We then determined combinations of $V_{s}$ values for the different layers that predict a fundamental resonance at the frequencies of peak amplitude in the observed spectral ratios. Because of the approximate nature of the one-dimensional modeling, we did not attempt to model the detailed shape of the observed spectral ratios. Neither did we adjust model parameters to match the amplitude of the observed spectral-ratio peaks.

At each station, we determined the depth to bedrock and to the top of the till layer using adjacent borehole data (Table 1) and fixed the thickness of the shallowest sediment layer (layer 1) at $3.8 \mathrm{~m}$. For the bedrock we assumed a Poisson's ratio of 0.25 , and assigned the $S$-wave bedrock velocity a value of $2125 \mathrm{~m} / \mathrm{sec}$. Poisson's ratios for the sediment layers are less certain. For the shallowest soft-sediment layer, we used a fixed shear-wave velocity of $120 \mathrm{~m} / \mathrm{sec}$, slightly higher than the $V_{s}$ for the upper few meters of soft soil in San Francisco Bay (Borcherdt and Gibbs, 1976; Hough, 1990) and Flushing Meadows, New York (Field et al., 1990). Shear-wave velocities in the second soft-sediment layer (layer 2) were allowed to vary from 150 to $800 \mathrm{~m} / \mathrm{sec}$, and in the till (layer 3) from 500 to $2000 \mathrm{~m} / \mathrm{sec}$, with the constraint that impedance must increase with depth. The shallow sediments, till, and bedrock were assigned densities of $1.6,1.8,1.9$, and $2.5 \mathrm{~g} / \mathrm{cm}^{3}$, and $Q^{\prime} \mathrm{s}$ of $5,10,20$, and 500 . These values are consistent with measurements from similar sediment and rock types (e.g., Joyner et al., 1976; Hough, 1990; Field et al., 1990; Boore and Joyner, 1991).

Although certain layer parameters were fixed in order to reduce the number of degrees of freedom in the modeling procedure, none of these assumptions introduced serious bias in the above analysis. Variations in bedrock velocity 
a)

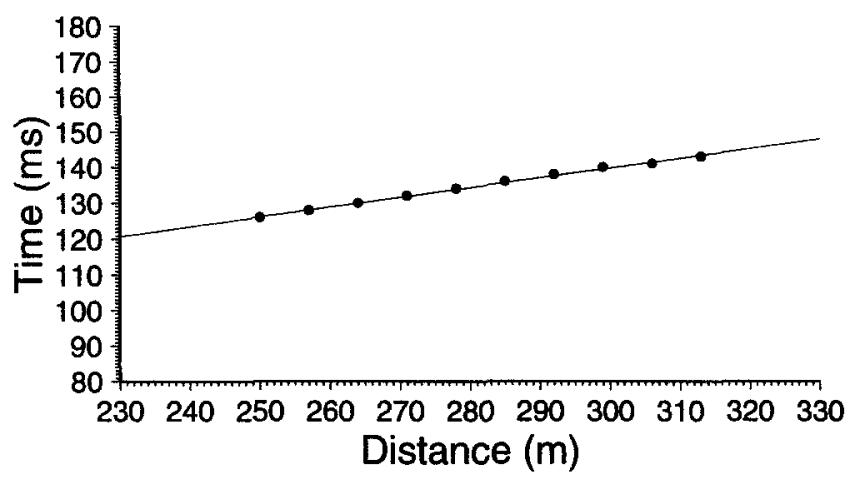

b)

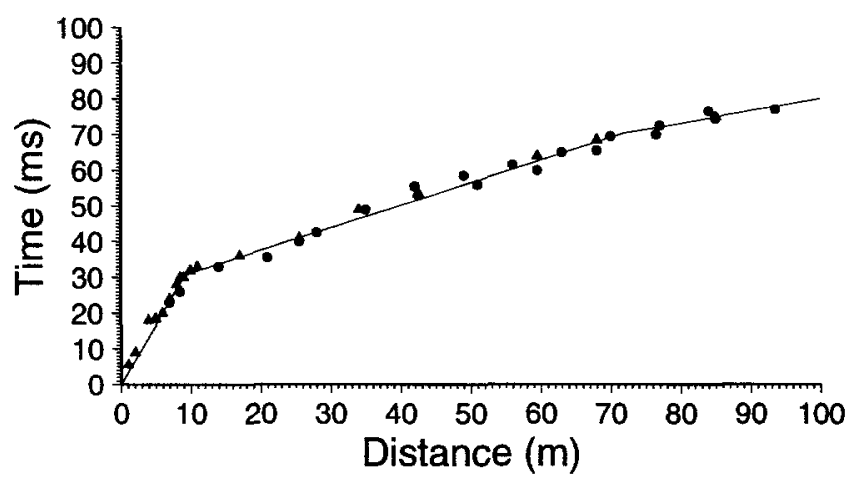

Figure 5. (a) Travel-time curve collected during the first refraction experiment (location shown by line segment 1 in Fig. 1a) when a single pile-driver drop was recorded over a W-E 12-channel refraction line with a sensor spacing of $7.0 \mathrm{~m}$. Circles indicate observed travel times, and the solid line shows the predicted travel times for a bedrock layer $V_{p}$ of 3680 $\mathrm{m} / \mathrm{sec}$. (b) Travel-time curve collected during the second refraction experiment (location shown by line segment 2 in Fig. 1a). Stacked sledgehammer hits at distances of 1 to $96 \mathrm{~m}$ on two E-W lines with sensor spacings of 1.0 and $8.5 \mathrm{~m}$ (triangles) and on two $\mathrm{W}-$ $E$ lines with spacings of 7.0 and $8.5 \mathrm{~m}$ (circles) were recorded. The solid lines show the predicted travel times for a four-layer velocity model: 0 to $3.8 \mathrm{~m}, V_{p}$ $=300 \mathrm{~m} / \mathrm{sec} ; 3.8$ to $19.2 \mathrm{~m}, V_{p}=1580 \mathrm{~m} / \mathrm{sec} ; 19.2$ to $23.7 \mathrm{~m}, V_{p}=2900 \mathrm{~m} / \mathrm{sec}$; depths $>23.7 \mathrm{~m}, V_{p}=$ $3680 \mathrm{~m} / \mathrm{sec}$.

would alter the amplitude, but not the frequency of the fundamental resonance peak. Variations in layer-1 velocity primarily affect the transfer functions at frequencies greater than 4 to $5 \mathrm{~Hz}$. The observed spectral ratios do not contain the higher frequency harmonics predicted by the one-dimensional transfer functions. However, this result is not surprising given that the valley structure is not in fact plane layered, and that resonance overtones are expected to be more sensitive to deviations from one-dimensional structure than the fundamental mode. The $Q$ and density values assumed in the one-dimensional models also do not bias the conclusions of the transfer-function modeling. Physically reasonable vari-
Table 1

Sediment-Layer Thicknesses (m)

\begin{tabular}{ccc}
\hline Site & $\begin{array}{c}\text { Soft Sediment } \\
\text { (Layers I and 2) }\end{array}$ & Till (Layer 3) \\
\hline A1 & 47.0 & 6.0 \\
A2 & 46.0 & 15.0 \\
B1 & 25.0 & 5.0 \\
B2 & 24.0 & 6.5 \\
C1 & 18.0 & 8.0 \\
C2 & 22.5 & 4.0 \\
D1 & 8.0 & - \\
D2 & 22.0 & 4.5 \\
R1 & $<4.0$ & - \\
R2 & $<4.0$ & - \\
\hline
\end{tabular}

Table 2

Best-Fitting Layer-2 $V_{s}(\mathrm{~m} / \mathrm{sec})$

\begin{tabular}{cccc}
\hline Site & Till $V_{s}=800$ & Till $V_{s}=1400$ & Till $V_{s}=2000$ \\
\hline A1 & 325 & 275 & 275 \\
A2 & 500 & 350 & 325 \\
B1 & 275 & 250 & 250 \\
B2 & 275 & 250 & 250 \\
C1 & 275 & 250 & 250 \\
C2 & 275 & 250 & 250 \\
\hline
\end{tabular}

ations in $Q$ and density have little impact on the frequencies at which the predicted resonance peaks occur, and their effect on the predicted amplitude of the fundamental resonance peak is within the uncertainties of the observational results.

For all valley stations where depth to bedrock exceeds $10 \mathrm{~m}$ (A1, A2, B1, B2, C1, C2, D2), with one exception (D2), one-dimensional transfer-function fundamental resonances provide a good fit to the frequencies of the observed spectral-ratio peaks from both horizontal components. Transfer functions were computed for a wide range of layer2 and layer-3 velocities. Best-fitting layer- $2 V_{s}$ values for each site show the smallest variations between sites for layer-3 velocities in the range of 1400 to $2000 \mathrm{~m} / \mathrm{sec}$ (Table 2 ). For this layer-3 $V_{s}$ range, layer-2 velocities do not vary significantly with changes in layer-3 velocity. Transfer functions predicted at these stations for a layer-3 velocity of 1400 $\mathrm{m} / \mathrm{sec}$ and the associated best-fitting layer- 2 velocity (Table 2) are shown in Figure 4 (bold solid lines). Although we did not alter model parameters to match the observed spectralratio amplitudes, the peak amplitudes of the spectral ratios and predicted transfer functions are generally consistent within a factor of 2 . With the exception of site A2, we found that theoretical fundamental resonance amplitudes generally underpredict the observed ratio amplitudes. Interestingly, Field et al. (1992) found that theoretical one-dimensional transfer functions underpredict the amplitude of site response inferred from sediment/hard-rock ratios of weakmotion recordings in the San Francisco Bay area, also by a factor of approximately 2 . At station D2, the shapes of the 
$\mathrm{NS} / \mathrm{V}$ and EW/V spectral ratios differ significantly. The NS/ $\mathrm{V}$ ratio at $\mathrm{D} 2$ is well-matched by the fundamental resonance of the one-dimensional transfer function for a layer-2 velocity of $225 \mathrm{~m} / \mathrm{sec}$ and a layer-3 velocity of $1400 \mathrm{~m} / \mathrm{sec}$ (bold solid lines in Fig. 4d). This model is similar to those that provide good fits to the other deeper sediment sites (Table 2, Figs. 4a, 4b, and 4c). However, while the EW/V and NS/ $\mathrm{V}$ ratios at $\mathrm{D} 2$ are consistent at frequencies greater than 2 $\mathrm{Hz}$, the EW/V ratio contains much higher amplitudes in the $0.5-$ to $1.5-\mathrm{Hz}$ range. The anomalous low-frequency energy on the EW component of station D2 may signify an unknown low-frequency noise source local to the site. It could also represent a polarized vibration from one of the surrounding bridges or highway overpasses, although no anomalous energy is observed on the EW component of nearby station $\mathrm{C} 2$.

At stations B1, B2, C1, and C2, the best-fitting layer-2 velocity is $250 \mathrm{~m} / \mathrm{sec}$. Given that the thickness of the softsediment layer is similar at these sites, the agreement in layer-2 velocities suggests that the observed spectral peak represents a robust estimate of the local site response. The best-fitting layer-2 velocity is $275 \mathrm{~m} / \mathrm{sec}$ at station Al and $350 \mathrm{~m} / \mathrm{sec}$ at station A2. Depth to bedrock at these sites (53 $\mathrm{m}$ at $\mathrm{A} 1$ and $61 \mathrm{~m}$ at $\mathrm{A} 2$ ) is significantly larger than at the other stations. The rough correlation between layer- 2 velocity and bedrock depth could reflect greater compaction in the deeper portion of the soft sediments and till. An increase in $V_{p}$ with depth within layer 2 is suggested by the slight curvature of the observed travel times about the best-fitting average $V_{p}$ value (Fig. 5b). However, the valley containing stations A1 and A2 also narrows with depth, and the apparent increase in soft-sediment velocity may not be real. Rather, it may reflect a locally two-dimensional sediment resonance at these sites, which would reduce the frequency of the fundamental resonance relative to the value predicted from a one-dimensional model (Bard and Bouchon, 1985). In either case, the predicted transfer functions provide a good fit to observed spectral ratios for reasonable values of sediment and bedrock velocities, and we therefore conclude that the $1.5-$ to $3.0-\mathrm{Hz}$ spectral peak observed at valley sites is plausibly explained by shear-wave resonance in the sediment column.

\section{Conclusions}

In spectral ratios (horizontal component/vertical component) from ambient-noise recordings at 10 sites within Providence, Rhode Island, we observed peaks at frequencies of 1.5 to $3.0 \mathrm{~Hz}$ at all sites where sediment thicknesses exceed $10 \mathrm{~m}$, and relatively flat spectral ratios at two sites where the sediment cover is thin $(<4 \mathrm{~m})$. Using a one-dimensional reflection matrix technique, we found that the 1.5to $3.0-\mathrm{Hz}$ spectral peaks observed at deep sediment sites are matched by the frequency of the fundamental resonance predicted for local sediment-layer thicknesses and velocities. We conclude that the peaks observed in the spectral ratios for valley sites may be explained by shear-wave resonance in the valley sediments.

If site response to earthquake ground motion is similar to the resonances apparently excited by ambient microtremors, our results suggest that the unconsolidated sediment layers beneath downtown Providence have the potential to amplify earthquake energy at frequencies that are potentially damaging to 2- to 5-story buildings and other engineered structures. These conclusions may also apply to other bedrock valleys with similar dimensions and sediment/bedrock impedance contrasts, for instance the Quinnipiac River valley in New Haven, Connecticut, and portions of the Charles River basin in metropolitan Boston, Massachusetts.

\section{Acknowledgments}

Research supported by the U.S. Geological Survey (USGS), Department of the Interior, under USGS Award Number 1434-92-G-2166. The views and conclusions contained in this document are those of the authors and should not be interpreted as necessarily representing the official policies, either expressed or implied, of the U.S. Government. Seismometers were provided by the National Center for Earthquake Engineering Research (NCEER). Thanks to D. W. Forsyth, L. Seeber, P. R. Slice, and numerous Brown University geophysics students for their assistance in the field, and to $\mathrm{M}$. Imse of the Providence Convention Center Authority and M. Unger of the C.E. Maguire Group for access to geotechnical reports.

\section{References}

Bard, P.-Y. and M. Bouchon (1985). The two-dimensional resonance of sediment-filled valleys, Bull. Seism. Soc. Am. 75, 519-541.

Beresnev, I. A., K.-L. Wen, and Y. T. Yeh (1995). Seismological evidence for nonlinear elastic ground behavior during large earthquakes, Soil Dyn. Earthquake Eng. 14, 103-114.

Berger, Louis, and Associates, Inc. (1992). Narragansett Bay Commission Combined Sewer Overflow Project: Project Plan, Narragansett Bay Commission, Providence, Rhode Island.

Bierschenk, W. H. (1959). Ground-water resources of the Providence Quadrangle, Rhode Island, Rhode Island Water Resources Coordinating Board, Rhode Island Geological Bull. 10.

Boore, D. M. and W. B. Joyner (1991). Estimation of ground motion at deep-soil sites in eastern North America, Bull. Seism. Soc. Am. 81, $2167-2185$.

Borcherdt, R. D. (1970). Effects of local geology on ground motion near San Francisco Bay, Bull. Seism. Soc. Am. 60, 29-61.

Borcherdt, R. D. and J. F. Gibbs (1976). Effects of local geology conditions in the San Francisco Bay region on ground motions and intensities of the 1906 earthquake, Bull. Seism. Soc. Am. 66, 467-500.

Chin, B.-H. and K. Aki (1991). Simultaneous study of the source, path, and site effects on strong ground motion during the 1989 Loma Prieta earthquake: a preliminary result on pervasive non-linear site effects, Bull. Seism. Soc. Am. 81, 1859-1884.

Darragh, R. B. and A. F. Shakal (1991). The site response of two rock and soil station pairs to strong and weak ground motion, Bull. Seism. Soc. Am. 81, 1885-1899.

Field, E. H., S. E. Hough, and K. H. Jacob (1990). Using microtremors to assess potential earthquake site response: a case study in Flushing Meadows, New York City, Bull. Seism. Soc. Am. 80, 1456-1480.

Field, E. H., K. H. Jacob, and S. E. Hough (1992). Earthquake site response estimation: a weak motion case study, Bull. Seism. Soc. Am. 82, 2283-2307.

Field, E. H. and K. H. Jacob (1993). The theoretical response of sediment layers to ambient seismic noise, Geophys. Res. Lett. 20, 2925-2928. 
Field, E. H. and K. H. Jacob (1995). A comparison and test of various site response estimation techniques, including three that are non-reference site dependent, Bull. Seism. Soc. Am. (in press).

Field, E. H., A. Clement, V. Aharonian, S. E. Hough, P. A. Friberg, T. O. Babaian, S. S. Karapetian, S. M. Hovanessian, and H. A. Abramain (1995). Earthquake site response study in Giumri (formerly Leninakan), Armenia, using ambient noise observations, Bull. Seism. Soc. Am. 85, 349-353.

Finn, W. D. L. (1991). Geotechnical engineering aspects of microzonation, in Proc. 4th Int. Conf. on Seismic Zonation, Stanford, California, Vol. $1,199-259$.

Fischer, K. M. and S. E. Hough (1992). Site response in Providence, Rhode Island: constraints from ambient noise measurements, Seism. Res. Lett. 63, 525-532.

Haley and Aldrich, Inc. (1990a). Report on subsurface investigations and foundation design studies, Convention Center Complex-Garage, Providence, Rhode Island, Cannon, Inc., Boston, Massachusetts.

Haley and Aldrich, Inc. (1990b). Report on subsurface investigations and foundation design studies, Providence Convention Center, Providence, Rhode Island, Howard Needles Tammen and Bergendoff, Boston, Massachusetts.

Hough, S. E. (1990). Constraining sediment thicknesses in the San Francisco Bay area using observed resonances and P-to-S conversions, Geophys. Res. Lett. 17, 1469-1472.

Hough, S. E., L. Seeber, A. Rovelli, L. Malagnini, and A. DeCesare (1992). Ambient noise and weak motion excitation of sediment resonances: results from the Tiber Valley, Italy, Bull. Seism. Soc. Am. 82, 11861205.

Joyner, W. B., R. E. Warrick, and A. A. Oliver, III (1976). Analysis of seismograms from a downhole array in sediments near San Francisco Bay, Bull. Seism. Soc. Am. 66, 937-958.

Kagami, H., C. M. Duke, G. C. Liang, and Y. Ohta (1982). Observation of 1-to 5-second microtremors and their application to earthquake engineering, Part 2: evaluation of site effect upon seismic wave amplification due to extremely deep soil deposits, Bull. Seism. Soc. Am. 72, 987-998.

Kagami, H., S. Okada, K. Shiono, M. Oner, M. Dravinski, and A. K. Mal (1986). Observation of 1- to 5-second microtremors and their application to earthquake engineering, Part 3: a two-dimensional study of site effects in the San Fernando Valley, Bull. Seism. Soc. Am. 76, 1801-1812.
Kanai, K. and T. Tanaka (1961). On microtremors VIII, Bull. Earthquake Res. Inst. Tokyo Univ. 39.

Kennett, B. L. N. and N. J. Kerry (1979). Seismic waves in a stratified half space, Geophys. J. R. Astr. Soc. 57, 557-583.

Lermo, J., M. Rodriguez, and S. K. Singh (1988). The Mexico earthquake of September 19, 1985-natural periods of sites in the Valley of Mexico from microtremor measurements and from strong-motion data, Earthquake Spectra 4, 805-814.

Lermo, J. F., S. Francisco, and J. Chavez-Garcia (1993). Site effect evaluation using spectral ratios with only one site, Bull. Seism. Soc. Am. 83, 1574-1594.

Maguire, C. E., Inc. (1986). Civic Center Interchange Contract 2, RI Department of Transportation, Providence, Rhode Island.

Maguire, C. E., Inc. (1990). Memorial Boulevard Extension Project Contract 5, RI Department of Transportation, Providence, Rhode Island.

Nakamura, Y. (1989). A method for dynamic characteristics estimation of subsurface using microtremor on the ground surface, Quarterly Report of the Railway Technical Research Institute, 30.

Ohta, Y. H., N. Kagami, N. Goto, and K. Kudo (1978). Observation of 1to 5-second microtremors and their application to earthquake engineering. Part 1. Comparison with long-period accelerations at the Tokachi-Oki earthquake of 1968, Bull. Seism. Soc. Am. 68, 767-779.

Okamato, S. (1973). Introduction to Earthquake Engineering, University of Tokyo Press, Tokyo, Japan.

Smith, J. H. (1956). Surficial geology of the Providence quadrangle, Rhode Island, U.S. Geol. Surv. Geol. Quad. Map 84.

Udwadia, F. E. and M. D. Trifunac (1973). Comparison of earthquake and microtremor ground motions in El Centro, California, Bull. Seism. Soc. Am. 63, 1227-1253.

U.S. Geological Survey (1975). 7.5 minute topographic quadrangle map of Providence, Rhode Island, scale 1:24,000.

Department of Geological Sciences

Brown University

Providence, Rhode Island, 02912

(K.M.F., L.A.S., E.G., C.E.N., E.G.R.)

U.S. Geological Survey

Pasadena, California, 91106

(S.E.H.)

Manuscript received 10 October 1994. 